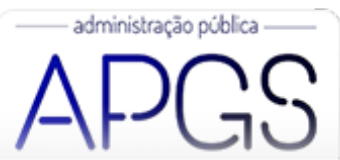

Administração Pública e Gestão Social ISSN: 2175-5787

apgs@ufv.br

Universidade Federal de Viçosa

Brasil

\title{
Rede de combate à escravidão contemporânea: De Jure ou De Facto?
}

Castro Fonseca de Moura, Paula Renata; Braz Arcanjo, Cecília; Costa Cavalcante, Pedro Luiz Rede de combate à escravidão contemporânea: De Jure ou De Facto?

Administração Pública e Gestão Social, vol. 12, núm. 4, 2020

Universidade Federal de Viçosa, Brasil

Disponible en: http://www.redalyc.org/articulo.oa?id=351564289010

Esta obra está bajo una Licencia Creative Commons Atribución-NoComercial-SinDerivar 3.0 Internacional. 


\section{Rede de combate à escravidão contemporânea: De Jure ou De Facto?}

Network against modern slavery: De Jure or De Facto?

Red contra la esclavitud moderna: De Jure o De Facto?

Paula Renata Castro Fonseca de Moura

Universidade de Brasilia, Brasil

Redalyc: http://www.redalyc.org/articulo.oa?

paularenatafdr@yahoo.com.br

id $=351564289010$

Cecilia Braz Arcanjo

Universidade de Brasilia, Brasil

ceciliabraz@unb.br

Pedro Luiz Costa Cavalcante

Instituto de Pesquisa Econômica Aplicada (Ipea), Brasil

cavalcante.pedro@gmail.com

Recepción: 25 Marzo 2019

Aprobación: 13 Enero 2020

Publicación: 01 Octubre 2020

\section{Resumo:}

O artigo analisa o funcionamento da rede de atores que desenvolvem ações no âmbito do II Plano Nacional para a Erradicação do Trabalho Escravo (II PNETE), mais especificamente aquelas direcionadas a fomentar a reforma agrária como forma de enfrentamento do problema. O objetivo foi explorar se a rede formalmente estabelecida pelo plano (de jure) atua efetivamente (de facto) na política de combate e prevenção ao trabalho escravo no país. Foi realizada pesquisa qualitativa, com utilização da técnica de grupo focal com atores relevantes para a execução da política. Os resultados indicam a carência de vínculos entre os atores indicados no Plano, revelando uma dissociação entre a formalização da política e sua dinâmica. Conclui-se que o foco das análises de redes deve atentar também para as práticas cotidianas das organizações, para assim avaliar os reais resultados e dificuldades do policy making.

PaLAVRAS-CHAVE: Redes de políticas públicas, implementação, trabalho escravo, Brasil.

\section{Abstract:}

The article analyzes the functioning of the network of actors that develop actions within the scope of the Second National Plan for the Eradication of Slave Labor, specifically those initiatives aimed at fomenting agrarian reform as a way of dealing with the problem. The objective was to explore whether the network formally established by the Plan (de jure) effectively acts (de facto) on the policy of combat and prevention of slave labor in Brazil. A qualitative research was carried out, using the focus group technique with relevant actors for the execution of the policy. The results indicate the lack of links among the actors specified in the Plan, revealing a dissociation between the formalization of the policy and its dynamics. It is concluded that the focus of the networks analysis should also consider the daily practices of organizations, in order to evaluate the real results and difficulties of policy making.

KEYWORDS: Public policy networks, implementation, slavery, Brazil.

\section{Resumen:}

El artículo analiza el funcionamiento de la red de actores que desarrollan acciones en el ámbito del II Plan Nacional para la Erradicación del Trabajo Esclavo, más específicamente, aquellas dirigidas a fomentar la reforma agraria como forma de afrontamiento del problema. El objetivo fue explorar si la red formalmente establecida por el plan (de jure) actúa efectivamente (de facto) en la política de combate y prevención al trabajo esclavo. Se realizó una investigación cualitativa, con utilización de la técnica de grupo focal con actores relevantes para la ejecución de la política. Los resultados indican la carencia de vínculos entre los actores indicados en el Plan, lo que señala una disociación entre la formalización de la política y su dinámica. Se concluye que el foco de los análisis de redes debe atentar también para las prácticas cotidianas de las organizaciones, para así evaluar los reales resultados y dificultades del policy making. 
Paula Renata Castro Fonseca de Moura, et al. Rede de combate À escravidão contemporânea: De Jure o...

Palabras ClaVe: Redes de políticas públicas, implementación, trabajo esclavo, Brasil.

\section{INTRODUÇÃO}

O presente estudo parte da concepção de redes de políticas como uma forma específica de governança, ou seja, como mecanismo de mobilização de recursos políticos em situações nas quais esses recursos estão amplamente dispersos entre atores públicos e privados, os quais formam elos para troca de recursos que constituem a estrutura de determinada rede (Börzel, 1998). Nesse sentido, as redes são respostas aos problemas de eficácia das políticas públicas, constituindo teias de relações relativamente estáveis, capazes de mobilizar e juntar recursos dispersos para que a ação coletiva ou paralela possa ser desenvolvida no sentido da solução de uma política comum (Börzel, 1998).

Genoino e Siqueira (2016) destacam que as pesquisas acerca das relações entre diversos atores na implementação de políticas públicas, incluindo os processos de descentralização do poder público para demais setores da sociedade, têm sido cada vez mais abordadas na administração pública. Silva e Coto (2015), por sua vez, ponderam que o Estado, visando à melhoria da prestação de serviços públicos, tem estimulado esse tipo de articulação para o desenvolvimento das políticas sociais, de modo que as redes têm se apresentado como uma estratégia adotada pelo poder público, envolvendo diversos atores sociais em prol da efetividade das políticas públicas. É cada vez mais comum a existência de políticas públicas que atualmente seguem o molde de articulação em redes, constituindo a mobilização e articulação de atores em estratégias fundamentais para a implementação das políticas públicas (Silva \& Coto, 2015).

Nesse contexto, a política pública para erradicação do trabalho escravo contemporâneo no Brasil é um exemplo de política complexa e que envolve uma cadeia de atores estatais e não estatais para sua execução. As diversas iniciativas governamentais para o combate a esse tipo de exploração evidenciam o envolvimento de uma rede de atores na formulação e implementação da política e a existência de interdependência entre esses atores (Monteiro \& Fleury, 2014).

Entendida como a forma mais que qualificada de superexploração do trabalho (Brito, 2010), o trabalho em condição análoga à de escravo, ou trabalho escravo contemporâneo, constitui uma grave violação de direitos humanos (Bicudo, 2008; Organização das Nações Unidas [ONU], 2016) que persiste no Brasil, mesmo após a abolição da escravatura, tanto no meio urbano como no meio rural, uma vez que práticas coercitivas de imposição da força de trabalho continuaram a compor a história do campo brasileiro (Organização Internacional do Trabalho [OIT], 2011).

Atualmente em vigor, o II Plano Nacional para a Erradicação do Trabalho Escravo (II PNETE) prevê medidas que visam a fomentar a reforma agrária nas regiões de origem, aliciamento e resgate de trabalhadores, como forma de combate e prevenção ao trabalho escravo nessas regiões, além de prever estratégias de reinserção social dos trabalhadores resgatados.

A complexidade da política para erradicação do trabalho escravo é evidenciada pela previsão de outras políticas sociais como instrumento para sua efetivação, o que reforça a demanda pelo envolvimento de diversos atores na execução de cada ação do II PNETE, inclusive entidades da sociedade civil. Assim, o plano procura constituir formalmente a participação dessas organizações de forma colaborativa, direcionadas à implementação das ações planejadas, indicando os atores responsáveis por cada ação e os respectivos atores parceiros.

Não obstante, é notório que a inclusão formal, ou de jure, de organizações em planos de atuação abrangentes e complexos, como o caso do II PNETE, não necessariamente reflete na efetiva participação dos mesmos no processo de formulação e implementação da política pública (policy making). Diante disso, este artigo possui como objetivo principal explorar se a rede formalmente estabelecida pelo plano atua efetivamente, de facto, na política de combate e prevenção ao trabalho escravo no país. Em outras palavras, a 
pesquisa visa avaliar em que medida a formalização da participação de atores em uma rede de política pública realmente reflete no seu ativo envolvimento no policy making.

Para tanto, foi necessário identificar os atores partícipes e seus papeis na implementação das ações adotadas, especificamente, na execução da política de reforma agrária como um instrumento do combate ao trabalho escravo contemporâneo. Em seguida, investigou-se também as relações entre eles e, a partir daí, foi mapeada a rede de atores que participam de facto do processo de implementação dessas ações. Na metodologia, além da análise de conteúdo, documental, revisão bibliográfica acerca do II PNETE, aplicou-se ainda pesquisa de grupo focal com representantes de diferentes organizações da rede.

Além desta introdução, a próxima parte discorre sobre os marcos teóricos da análise de redes de políticas públicas. A terceira seção dedica-se à caracterização e contextualização da escravidão contemporânea. Posteriormente são apresentadas as estratégias metodológicas utilizadas na pesquisa, resultados obtidos e conclusões.

\section{Fundamentos Teóricos}

O estudo das redes envolve uma variedade de campos científicos, possuindo assim uma difícil e complexa definição. O termo "redes" tem sido usado em múltiplas circunstâncias, com significados distintos, existindo a necessidade de se definir o seu conceito em determinados contextos de utilização e finalidades (Frey, Penna, \& Czajkowski, 2005).

Fleury (2005) aponta diferentes abordagens do fenômeno, demonstrando a dificuldade de consenso quanto à sua definição na literatura. A autora conclui que os estudos sobre redes indicam uma mudança na relação entre níveis governamentais e na relação entre Estado e sociedade, requerendo um novo paradigma para a análise da administração das políticas públicas, capaz de responder às necessidades e características do contexto atual (Fleury, 2005).

Apesar da confusão de inúmeros conceitos e contextos de uso do termo "redes", no que diz respeito às redes de políticas públicas, Börzel (1998) afirma haver um entendimento mínimo de definição, qual seja, um conjunto de relações relativamente estáveis, de natureza não hierárquica e interdependentes, conectando uma variedade de atores que compartilham interesses comuns com relação à política pública e que trocam recursos, reconhecendo que a cooperação é o melhor caminho para alcançar esses objetivos (Börzel, 1998).

O surgimento das redes de políticas públicas é apontado como consequência dos problemas derivados de uma sociedade cada vez mais plural e complexa, com os quais as estruturas institucionais são incapazes de lidar. Koppenjan e Klinj (2004) enfatizam que esses problemas sociais complexos necessitam de interações e gerenciamento com uma configuração de dependências mútuas em torno das soluções. Assim, os diversos tipos e formas de arranjos interorganizacionais tornam-se mecanismos necessários para oferecer respostas e soluções às questões complexas trazidas à tona por sociedades cada vez mais dinâmicas. Bispo e Santos (2017), por sua vez, afirmam que as redes de políticas públicas se configuram como um novo desenho de estruturação de políticas e programas públicos, caracterizado pela complexidade das relações entre os diversos atores envolvidos.

Observa-se, assim, que muitos estudos percebem as redes de políticas como uma forma particular de governança dos sistemas políticos modernos, centralizando-se na estrutura e nos processos pelos quais as políticas públicas se formam (Monteiro \& Fleury, 2014). Tais estudos indicam como pressuposto dessa percepção o processo de transformação pelo qual as democracias ocidentais têm passado, descentralizando o exercício do poder do Estado e fazendo com que surjam arranjos compostos por atores públicos, privados e públicos não-governamentais (Fleury \& Ouverney, 2007).

Schneider (2005) também indica que o conceito de rede, juntamente com o de governança, se refere a uma transformação do Estado e de sua relação com a sociedade, bem como indica que a solução de problemas 
políticos através de políticas públicas é possível apenas com base em novas estruturas políticas, concebendo, assim, as redes de políticas públicas como uma nova forma de governança política.

Nesse contexto, as redes de políticas públicas configuram-se como estratégias adotadas pelo Estado a fim de melhorar a prestação dos serviços públicos, estimulando a articulação de diversos atores sociais para o desenvolvimento das políticas (Silva \& Coto, 2015). Por esse motivo é que muitas políticas públicas atualmente seguem o modelo de articulação em redes, prevendo a mobilização e associação de atores como estratégia fundamental de implementação de política pública, especialmente por meio de redes de cooperação, o que indica aumento da interdependência entre agentes públicos e privados (Silva \& Coto, 2015).

Tem-se, assim, o relacionamento entre os atores como um fator predominante para a concepção de redes, sendo o foco no relacionamento entre os atores a característica mais determinante na análise de redes (Frey et al., 2005). Koppenjan e Klijn (2004) afirmam que o ponto de partida na abordagem da rede são atores mutuamente dependentes na conquista de objetivos.

Quanto às redes de políticas públicas, o exercício da governança por meio de redes demonstra a necessidade da construção de relações de interdependência e de intercâmbio de recursos, baseados na concepção da complementaridade de interesses e confiança (Fleury \& Ouverney, 2007).

Diante do exposto, observam-se três fatores que se encontram presentes nas diversas abordagens que envolvem os estudos sobre redes: A multiplicidade de atores, as relações entre eles e os recursos trocados. Bispo e Santos (2017) ressaltam ainda que a forma de comunicação entre os atores que compõem a rede, bem como as relações de poder, são elementos fundamentais. Fleury (2005) indica como elementos chaves a serem considerados na análise das redes os atores, os recursos, as percepções e as regras, visto que são seus elementos constitutivos, destacando, por outro lado, que uma rede envolve também a construção de um objetivo maior que se torna um valor compartilhado entre os atores integrantes da rede para além dos objetivos particulares de cada um. Börzel (1998) também entende que os integrantes de uma rede compartilham um sistema específico de crenças ou de valores, bem como percebem de modo semelhante o problema, podendo assim influenciar nos resultados das políticas públicas (Börzel, 1998).

Para o presente estudo, elaborou-se o quadro teórico ilustrado no Quadro 1, a partir das categorias de análise indicadas pela literatura revisada (Bispo \& Santos, 2017; Fleury, 2005; Fleury \& Ouverney, 2007; Frey et al., 2005; Koppenjan \& Klijn, 2004).

Quadro 1 - Categorias de análise de redes de políticas públicas

\begin{tabular}{|l|l|}
\hline Categorias & Descrição \\
\hline $\begin{array}{l}\text { Atores } \\
\text { (identificação) }\end{array}$ & $\begin{array}{l}\text { Competências e (ou) atribuições Objetivos } \\
\text { particulares }\end{array}$ \\
\hline Relações & $\begin{array}{l}\text { Regras Comunicação Interdependência e } \\
\text { coordenação Interesses (complementariedade, } \\
\text { cooperação ou conflito) Confiança Relações de } \\
\text { poder }\end{array}$ \\
\hline Recursos & Informações (fluxos) Intercâmbio (trocas) \\
\hline $\begin{array}{l}\text { Valor } \\
\text { compartilhado }\end{array}$ & $\begin{array}{l}\text { Objetivo maior Percepção sobre o problema } \\
\text { Crenças compartilhadas }\end{array}$ \\
\hline
\end{tabular}

Assim, a presente pesquisa parte do pressuposto de que a análise de redes como ferramenta que possibilita apreender e compreender fenômenos sociais possui potencial explicativo para investigação de políticas públicas (Frey et al., 2005). A análise pretendida, no contexto dos desafios trazidos à gestão pública pelo modelo de implementação de políticas públicas em rede (Fleury, 2005), possibilita também avançar na investigação da forma como uma política é implementada pelos atores, o que pode consistir em um ponto de partida para análises posteriores sobre a implementação da política. Ademais, ao investigar a rede de política 
pública a partir da perspectiva dos atores partícipes, a pesquisa almeja superar a visão normativa e trazer evidências empíricas de que a formalização não é, necessariamente, uma estratégia suficiente para o seu efetivo funcionamento.

\section{O TRABALHO ESCRAVO CONTEMPORÂNEO}

A escravidão contemporânea não corresponde conceitualmente ao modo de escravidão que havia na Antiguidade ou à escravidão de povos africanos nas Américas (Figueira, 2004). Por esse motivo, utilizam-se alguns termos em complementação ao vocábulo "escravidão" para diferenciar o fenômeno atual dos eventos históricos passados, tal como a utilização do termo "análoga” no meio jurídico e governamental, que é a forma como o artigo 149 do Código Penal Brasileiro designa a relação (Figueira, 2004).

Não existem estatísticas oficiais quanto ao número exato de trabalhadores submetidos atualmente a condições análogas às de escravo, uma vez que se tratam de contratações informais. Entre 1995 e 2018, já foram resgatados 53.195 trabalhadores, nas inspeções realizadas pelo Ministério do Trabalho e Emprego (MTE), conforme dados sistematizados pela própria pasta.

Apenas em 1995 o governo brasileiro reconheceu a existência de trabalho escravo em seu território (OIT, 2007), ano em que foram criadas diversas estruturas governamentais para combater a escravidão moderna, entre as quais se destacam o Grupo Executivo de Repressão ao Trabalho Forçado (GERTRAF) e o Grupo Especial de Fiscalização Móvel (GEFM), coordenado pelo Ministério do Trabalho e Emprego (OIT, 2011). Já o I Plano Nacional para a Erradicação do Trabalho Escravo (I PNETE) foi lançado em 2003 e desde o seu lançamento houve elevação do número de operações e do número de resgates por operação. Nesse primeiro Plano, a ação prevista no item 53 foi a única que se referiu à execução da política de reforma agrária, colocando-a como medida voltada para a reinserção social do trabalhador resgatado.

Em 2008, quando da avaliação dos resultados da implementação do I PNETE, destacou-se o cumprimento total ou parcial de $68,4 \%$ das metas nele previstas, segundo avaliação da OIT, relativamente aos dois primeiros anos do Plano (OIT, 2007). Porém, reconheceu-se que os avanços ocorreram nas áreas de fiscalização e de conscientização dos trabalhadores, existindo pouco avanço na aplicação de medidas visando à diminuição da impunidade e ao aumento da garantia de emprego e reforma agrária nas regiões fornecedoras de mão de obra escrava. Consequentemente, o II Plano Nacional para a Erradicação do Trabalho Escravo (II PNETE) concentrou esforços nessas duas áreas (II Plano Nacional para a Erradicação do Trabalho Escravo, 2008), de modo que foram ampliadas as ações destinadas à promoção de reforma agrária, indicadas no Quadro 2. 
Quadro 2 - Ações do II PNETE relacionadas à reforma agrária

\begin{tabular}{|l|l|}
\hline \multicolumn{1}{|c|}{$\begin{array}{c}\text { Atores responsáveis e parceiros indicados no II } \\
\text { PNETE }\end{array}$} & \multicolumn{1}{c|}{$\begin{array}{c}\text { Atores envolvidos segundo participantes do grupo } \\
\text { focal }\end{array}$} \\
\hline Presidência da República & \\
\hline CONATRAE & CONATRAE \\
\hline Ministério Público Federal & Ministério Público Federal \\
\hline Ministério Público do Trabalho & Ministério Público do Trabalho \\
\hline Ibama/MMA & \multicolumn{1}{|c|}{ Atual MDH } \\
\hline Secretaria Especial de Direitos Humanos & $\begin{array}{l}\text { CPT, Sociedade Maranhense de Direitos } \\
\text { Humanos (SMDH) }\end{array}$ \\
\hline Sociedade civil & Ministério do Trabalho e Emprego \\
\hline Ministério do Trabalho e Emprego & \\
\hline Ministério da Justiça & Incra/MDA \\
\hline Ministério do Desenvolvimento Social & \\
\hline Incra/MDA $/$ Molia Federal $(P F)$ \\
\hline Governos Estaduais e Municipais & Policia Fodoral $(P R F)$ \\
\hline MEC & Policia Rodovia Federal \\
\hline
\end{tabular}

Fonte: Secretaria Especial dos Direitos Humanos (2008).

Assim, a identificação dos atores e o mapeamento das relações entre eles é relevante para a compreensão do processo de implementação das ações referidas, pois os atores mudam com o passar do tempo, bem como as interações entre eles (Lima \& D’Ascenzi, 2013).

\section{Procedimentos Metodológicos}

Considerando o objeto e os objetivos da pesquisa, esta se caracteriza como exploratória, pois visa a ampliar o conhecimento sobre um fenômeno específico pouco conhecido (Hair, Barry, Money, \& Samouel, 2005). A abordagem utilizada foi qualitativa, enfoque conceituado como aquele predominantemente utilizado para refinar as questões de pesquisa, sendo a sua ênfase compreender um fenômeno, sem a pretensão de medi-lo (Sampieri, Collado, \& Lucio, 2013), sendo a abordagem adequada para o fim aqui pretendido.

Além da análise de conteúdo de documentos oficiais, foi utilizada também a técnica do grupo focal para coleta de dados primários, definida como um tipo de entrevista realizada pelo pesquisador com os participantes em grupo (Creswell, 2010). Os grupos de foco reúnem dados relativos às opiniões de um grupo de pessoas que está envolvido em uma mesma situação (Collis \& Hussey, 2005) e consistem em entrevistas semiestruturadas que utilizam abordagem exploratória em pesquisas qualitativas (Hair et al., 2005). Assim, o grupo focal realizado possuiu como objetivo obter informações e opiniões acerca do desenvolvimento da reforma agrária como instrumento da política pública para erradicação do trabalho escravo, conforme ações previstas no II PNETE, e sobre a efetiva atuação dos atores envolvidos responsáveis pela execução dessas ações.

O grupo focal foi estruturado de modo a envolver profissionais que tivessem conhecimento e (ou) envolvimento com a implementação das ações objeto de análise. Por este motivo foram convidados servidores do Instituto Nacional de Colonização e Reforma Agrária (Incra), autarquia responsável pela política nacional de reforma agrária, bem como o coordenador, os ex-coordenadores, o coordenador substituto e excoordenadores substitutos da Comissão Nacional para a Erradicação do Trabalho Escravo (CONATRAE), responsável pela avaliação, coordenação e monitoramento das ações previstas no II PNETE, criada em 2003 por meio de decreto. Assim, a amostra do presente estudo classifica-se como não probabilística, tipo de amostra formada pelos elementos aos quais o pesquisador tem acesso, utilizados em pesquisas exploratórias e qualitativas (Gil, 2008). 
Foram feitos 14 convites, por meio de contato telefônico e alguns reforçados por meio de correio eletrônico, aos servidores do Incra e da CONATRAE, especificando o objeto de estudo e o objetivo da realização do grupo focal. Oito convidados externaram disponibilidade e concordância em participar do grupo, sendo que sete deles compareceram. Entre os participantes, seis são servidores do Incra, sendo um da área jurídica, um assessor da Presidência da autarquia, dois da área de desenvolvimento de projetos de assentamento, um da área de assistência técnica aos projetos de assentamento e um da área de fiscalização e controle de áreas. Todos os servidores contam com 10 anos ou mais de serviço na instituição. Da CONATRAE, participou um ex-coordenador da Comissão. Entende-se, assim, que o grupo foi formado por profissionais capazes de fornecer as informações necessárias ao desenvolvimento da pesquisa. Os participantes do grupo focal foram:

1. Servidor da Secretaria de Direitos Humanos, ex-coordenador da CONATRAE;

2. Servidor da Divisão de Fiscalização e Controle do Incra;

3. Servidor da Assessoria da Presidência do Incra;

4. Servidor da Procuradoria Federal Especializada do Incra;

5. Servidor da Coordenação-Geral de Desenvolvimento de Projetos de Assentamento do Incra;

6. Servidor da Coordenação Nacional de ATES do Incra;

7. Servidor da Coordenação Geral de Desenvolvimento de Assentamentos do Incra.

As questões do grupo focal foram elaboradas de modo a obter informações sobre três temas de investigação relevantes para compreensão da rede:

i) Entendimento dos participantes sobre a relevância da reforma agrária para a erradicação do trabalho escravo contemporâneo;

ii) Ações que foram implementadas e (ou) executadas pelo Incra e pelo CONATRAE, e

iii) Interação e (ou) relação entre os atores e identificação dos demais atores que participam da rede, com a descrição do relacionamento entre eles e recursos trocados.

Para alcançar os objetivos indicados e considerando as categorias de análise conforme marco teórico, foram feitas as perguntas dispostas no Quadro 3 aos participantes do grupo focal.

Quadro 3 - Questões aplicadas ao Grupo Focal 
Quadro 3 - Questões aplicadas ao Grupo Focal

\begin{tabular}{|c|c|c|}
\hline Objetivos & $\begin{array}{l}\text { Categoria de } \\
\text { análise } \\
\end{array}$ & $\begin{array}{l}\text { Perguntas aplicadas ao } \\
\text { grupo focal }\end{array}$ \\
\hline $\begin{array}{l}\text { Entendimento dos } \\
\text { participantes sobre } \\
\text { a relevância da } \\
\text { reforma agrária } \\
\text { para a erradicação } \\
\text { do trabalho } \\
\text { escravo } \\
\text { contemporâneo }\end{array}$ & $\begin{array}{l}\text { Valor } \\
\text { compartilhado }\end{array}$ & $\begin{array}{l}\text { De que maneira as ações } \\
\text { relacionadas à reforma } \\
\text { agrária podem contribuir } \\
\text { com o desenvolvimento } \\
\text { da politica para } \\
\text { erradicaçâo do trabalho } \\
\text { escravo? }\end{array}$ \\
\hline $\begin{array}{l}\text { Ações que foram } \\
\text { implementadase } \\
\text { (ou) executadas } \\
\text { pelo Incra e } \\
\text { CONATRAE }\end{array}$ & $\begin{array}{l}\text { Recursos e } \\
\text { açôes }\end{array}$ & $\begin{array}{l}\text { Como o Incra e a } \\
\text { CoNATRAE têm atuado } \\
\text { para implementar as } \\
\text { medidas previstas no II } \\
\text { PNETE relacionadas à } \\
\text { reforma agrária? Quais } \\
\text { as contribuições de } \\
\text { outros atores para a } \\
\text { execução dessas ações, } \\
\text { na sua opinião? }\end{array}$ \\
\hline $\begin{array}{l}\text { Relação entre os } \\
\text { atores e } \\
\text { identificação dos } \\
\text { demais atores que } \\
\text { participam da } \\
\text { rede, com a } \\
\text { descrição do } \\
\text { relacionamento } \\
\text { entre eles e os } \\
\text { recursos trocados }\end{array}$ & $\begin{array}{l}\text { Atores e } \\
\text { relacionamento }\end{array}$ & $\begin{array}{l}\text { Existe articulação entre } \\
\text { Incra e CoNATRAE para } \\
\text { a execução dessas ações? } \\
\text { E com outros atores da } \\
\text { sociedade em geral? } \\
\text { Quem são esses atores? } \\
\text { Como ocorrem essas } \\
\text { articulações? Acredita } \\
\text { que outros atores } \\
\text { poderiam se envolver na } \\
\text { execução dessas ações e } \\
\text { atualmente não se } \\
\text { envolvem? }\end{array}$ \\
\hline
\end{tabular}

Fonte: Elaboração dos autores.

Considerando que a triangulação é uma estratégia de pesquisa baseada na utilização de diversos métodos para a investigação de um mesmo fenômeno (Vergara, 2005), a presente pesquisa realizou a coleta de dados primários por meio da realização do grupo focal, conjugado com outros métodos de investigação, buscando garantir maior validade aos resultados obtidos.

Por fim, os dados foram analisados e categorizados conforme os quadros definidos no referencial teórico, explicitando os achados que, posteriormente, foram traduzidos em insumos para sua inserção no software Ucinet - Versão 6.644. Esse software, juntamente com o NetDraw - Versão 2.161, possibilitou a visualização do mapa da rede de atores envolvidos na implementação das ações da política pública objeto da análise.

\section{Rede De Jure ou De Facto? O caso do II PNETE}

A análise dos dados se deu a partir da análise do conteúdo das falas dos participantes do grupo focal, categorizando-os a partir da fundamentação teórica proposta. $\mathrm{O}$ foco direcionou-se na identificação dos atores, valores compartilhados, no modo de relacionamento e troca de recursos, bem como nas ações executadas por eles. Os resultados foram agrupados, em boa medida, nessas dimensões.

A diversidade de atores envolvidos é uma característica das redes de políticas públicas (Monteiro \& Fleury, 2014). A pesquisa permitiu identificar os principais atores envolvidos na execução de medidas de combate ao trabalho escravo contemporâneo no Brasil por meio de ações relacionadas à reforma agrária, conforme exposto no Quadro 4. 
Quadro 4 - Identificação dos atores

\begin{tabular}{|l|l|}
\hline $\begin{array}{l}\text { Atores responsáveis e } \\
\text { parceiros indicados no II } \\
\text { PNETE }\end{array}$ & $\begin{array}{l}\text { Atores envolvidos segundo } \\
\text { participantes do grupo focal }\end{array}$ \\
\hline Presidência da República & \\
\hline CONATRAE & CONATRAE \\
\hline Ministério Público Federal & Ministério Público Federal \\
\hline $\begin{array}{l}\text { Ministério Público do } \\
\text { Trabalho }\end{array}$ & $\begin{array}{l}\text { Ministério Público do } \\
\text { Trabalho }\end{array}$ \\
\hline Ibama/MMA & Atual MDH \\
\hline $\begin{array}{l}\text { Secretaria Especial de } \\
\text { Direitos Humanos }\end{array}$ & $\begin{array}{l}\text { CPT, Sociedade Maranhense } \\
\text { de Direitos Humanos (SMDH) }\end{array}$ \\
\hline $\begin{array}{l}\text { Sociedade civil } \\
\text { Ministério do Trabalho e } \\
\text { Emprego }\end{array}$ & $\begin{array}{l}\text { Ministério do Trabalho e } \\
\text { Emprego }\end{array}$ \\
\hline Ministério da Justiça & $\begin{array}{l}\text { Ministério do Desenvolvimento } \\
\text { Social }\end{array}$ \\
\hline Incra/MDA & Incra/MDA \\
\hline $\begin{array}{l}\text { Governos Estaduaise } \\
\text { Municipais }\end{array}$ & \\
\hline MEC & Policia Federal (PF) \\
\hline & $\begin{array}{l}\text { Polícia Rodoviária Federal } \\
\text { (PRF) }\end{array}$ \\
\hline & \\
\hline
\end{tabular}

Fonte: Elaboração dos autores.

Em negrito, os atores indicados no II PNETE e citados pelos participantes do grupo focal; em itálico, os atores citados pelo grupo focal e não indicados no Plano.

O primeiro achado ajuda a analisar o principal objetivo desta pesquisa, ou seja, em que medida a formalização da participação de atores em uma rede complexa de política pública realmente reflete no seu ativo envolvimento no policy making.

Observa-se que a Presidência da República, Ibama, Ministério da Justiça, Ministério do Desenvolvimento Social não foram mencionados pelos participantes do grupo focal, bem como nenhum governo estadual ou municipal, enquanto a Polícia Federal e a Polícia Rodoviária Federal foram mencionadas, embora não estejam indicadas no II PNETE como atores responsáveis ou parceiros pela execução das ações.

Tal resultado, embora não autorize a conclusão definitiva de que os atores não mencionados não executaram qualquer iniciativa a seus encargos prevista nas ações selecionadas pela pesquisa, sugere a ausência de relacionamento entre eles na implementação dessas ações, consistindo em um importante indicativo do funcionamento da rede proposta. Fica claro, com base nas percepções dos participantes do grupo, que a constituição e a atuação da rede de facto se difere da formalmente estabelecida no Plano (de jure).

Quanto à forma de relacionamento dos atores, a literatura indica que a existência da rede possibilita uma maior articulação entre eles, pois eles se relacionam mais entre si do que com outros atores fora da rede (Monteiro \& Fleury, 2014). Observou-se a existência de articulação, embora precária, entre Incra e CONATRAE.

Foi possível perceber ainda uma falha na definição das competências institucionais de cada ente, uma vez que as atribuições de cada órgão não se encontram bem delimitadas no Plano. Evidenciou-se também uma falta de alinhamento normativo-operacional para o intercâmbio de dados. As trocas de informações eram muitas vezes constituídas de maneira informal, determinadas pela proximidade entre as pessoas, percepção que é reforçada pelas seguintes falas (todas do Participante 4, não contestadas pelos demais): 


\begin{abstract}
"Na parte fundiária propriamente dita, a correlação, o cruzamento de dados utilizados da questão das ações de fiscalização. Eu não sei bem qual foi o nível de formalização disso daí, eu acho que chegou a ter algum tipo de instrumento, não sei se diretamente com a CONATRAE, mas com o Ministério do Trabalho, um acompanhamento do recebimento das indicações das ações de resgate pra fazer batimento com a questão fundiária, sempre muito no foco da obtenção”.

“(...) eles nunca conseguiram (...) um alinhamento fino no âmbito de um normativo operacional, que poderia ser normatizado, de quais os dados eventualmente que o Ministério do Trabalho devesse ou não fornecer ao Incra e o intercâmbio desses dados, (...) uma falta de normatização deixava cair em situações do tipo: Recebia um dado, não sabia se recebia via Ministério ou via CONATRAE, às vezes vinha de um ou vinha de outro, dependendo da época, porque tinha uma época que a relação virou muito pessoalizada (...)".

"Foram alguns fluxos administrativos implementados de recebimento desses processos, até onde eu me recordo, mais via CONATRAE (...). Eu não sei se tem muita clareza desse fluxo operacional, acho que ficou um fluxo muito mais pessoalizado (...) do que um fluxo administrativo (...)".
\end{abstract}

Essa característica da articulação entre os atores também foi encontrada no estudo de Monteiro e Fleury (2014), consistente no caráter personalizado das ações desenvolvidas, revelando que estas ainda não foram institucionalizadas como uma função a ser desempenhada pelas organizações, de modo que as ações de combate ao trabalho escravo ficam dependentes de pessoas mais envolvidas com o tema, o que reforça a relevância do olhar para a dimensão informal das redes.

Também foram mencionadas articulações entre o Incra e a CONATRAE com o Ministério do Trabalho e Emprego (tem) e entidades da sociedade civil, mais especificamente, a Comissão Pastoral da Terra (CPT), além do Ministério Público do Trabalho e Ministério Público Federal:

“O MTE porque coordena os grupos móveis que são os responsáveis pelos resgates dos trabalhadores. (...) A CPT como uma organização da sociedade civil que também faz esse trabalho de fiscalização, acolhe essas demandas (...). Em termos institucionais de Estado é fundamental nesse processo de resgate dos trabalhadores a Polícia Federal, o Ministério Público do Trabalho, o Ministério Público Federal, Polícia Rodoviária Federal, que são atores que comumente compõem os grupos móveis e são essenciais para o trabalho de resgate”. (Participante 1)

Interessante notar o destaque dado à atuação da CPT, que foi citada pela maioria dos participantes da pesquisa. A organização da sociedade civil desempenha um papel relevante no que diz respeito à produção de informações, especialmente por meio de acolhimento das denúncias e no fluxo de informação entre os atores:

\footnotetext{
"Movimentos que tenham organização maior como a CPT, que faz um acompanhamento da lista, faz inclusive um trabalho de consolidação de dados, um trabalho como organismo de ação social”. (Participante 4)

"O estágio da CPT tá pra além, (...) do que dispõe o próprio Ministério de Trabalho em termos de denúncia ou o próprio Disque 100 do Ministério dos Direitos Humanos, hoje, em relação a denúncias em relação a trabalho escravo e outras questões. O papel do movimento (...) para além da denúncia, é a ação de organização coletiva mesmo de ocupar determinada terra onde há evidências de irregularidade, obrigando (...) que o Incra faça uma fiscalização sobre aquela terra”. (Participante 1)

"Essa base social [trabalhadores resgatados da escravidão contemporânea] é uma base social de difícil organização (...). Tem a CPT, que coloca luz em cima desse tema e (...) acaba sendo procurada em muitos casos quando algum trabalhador desses consegue escapar ou faz a denúncia”. (Participante 7)
}

Quanto à interação entre Incra e CONATRAE e com outros atores colaboradores e responsáveis pela execução das ações selecionadas, observou-se uma fragilidade nos mecanismos de cooperação, bem como a importância de fortalecer essas relações. Percebeu-se que o relacionamento se dá principalmente em função da troca de informações, o que ocorre quando a CONATRAE e o MTE enviam dados ao Incra, no intuito de auxiliar ou dotar o órgão de informações que possam direcionar suas ações. Já em relação aos movimentos sociais, estes são responsáveis pela indicação de irregularidades, apontando a necessidade de atuação do Estado em determinadas áreas.

Considerando que a ferramenta de análise de redes permite a compreensão do fenômeno, inclusive a partir da sua visualização e representação gráfica (Frey et al., 2005), os resultados obtidos foram traduzidos em insumos para sua inserção no Ucinet. O preenchimento das relações utilizadas para construção da rede se deu a partir das informações colhidas no grupo focal. 
O critério utilizado para identificação dos atores e para construção das relações entre eles foi a citação expressa pelos participantes do grupo dos atores envolvidos na execução da política e da existência de relação entre eles. Dessa forma, há atores e relações que não foram mencionadas pelos participantes, motivo pelo qual não aparecem no mapa e as relações não foram representadas. Vale ressaltar que a análise de redes por meio da ferramenta Ucinet permite apenas uma espécie de fotografia, sendo incapaz de retratar a forma como as relações entre os atores ocorreram ao longo do tempo. Assim, obteve-se a seguinte representação gráfica da rede:

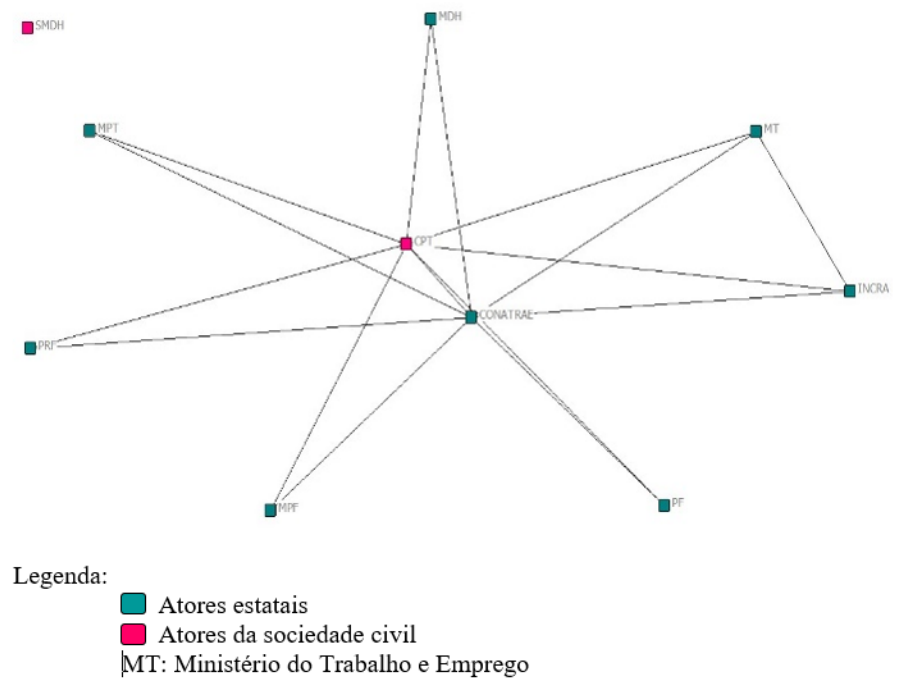

Figura 1 - Mapa dos atores envolvidos na implementação das ações selecionadas

Apesar de o mapa representar apenas a percepção dos participantes do grupo focal, ele fornece uma leitura interessante, evidenciando que o Incra, apesar de ser o ator com competência institucional para o desenvolvimento da política de reforma agrária, sendo o responsável pela execução de quatro das cinco ações aqui selecionadas, não é um ator que possui centralidade na rede, no que diz respeito à sua articulação com os demais atores envolvidos na execução da política.

A pesquisa também permitiu identificar e sintetizar as barreiras e dificuldades enfrentadas no relacionamento entre os atores. Dentre as principais barreiras mencionadas pelos participantes da pesquisa, vale destacar:

- Falta alinhamento normativo-operacional para a troca e (ou) intercâmbio de dados;

- Ausência de parâmetro que identifique o que é relevante para encaminhamento ao Incra;

- A troca de dados ocorria mais com base em relações pessoais, conforme a proximidade entre as pessoas;

- O Incra não pode fiscalizar a partir de denúncias de trabalho escravo feitas pelo movimento social, pois isso compete ao Ministério do Trabalho. O Incra só pode atuar a partir de indicação do MTE ("Lista Suja", por exemplo);

- Impossibilidade de atuação do Incra nas ações de fiscalização, em decorrência do grau de sigilo da atuação do Grupo Especial de Fiscalização Móvel;

- Ausência de articulação com outros órgãos e de ações dos municípios;

- Omissão histórica do Judiciário. Não existem condenações penais (impunidade).

Foi apontado, ainda, como um ator que poderia ou deveria estar mais presente nas ações de combate ao trabalho escravo, o Poder Judiciário, com críticas acerca de sua atuação no sentido de impedir a perpetuação da impunidade, o que também foi um achado do estudo de Monteiro e Fleury (2014):

"Em relação ao trabalho escravo, eu acho que existe uma omissão histórica (...) que mais contribui pra permanência do (...) problema, é a ausência do Judiciário. Você não vê, são raras as condenações (...). São raríssimas, acho que no Brasil a gente conta nas mãos o número de condenações por trabalho escravo." (Participante 1) 
No que diz respeito à identificação das ações executadas por cada ente, a análise documental permitiu identificar as suas responsabilidades na execução das ações do II PNETE e a análise das falas dos participantes do grupo focal revelou as estratégias de ação de cada um, conforme Quadro 5.

Quadro 5 - Resumo das ações desenvolvidas pelo Incra e pela CONATRAE

\begin{tabular}{|c|}
\hline INCRA \\
\hline $\begin{array}{l}\text { Cruzamento dos dados encaminhados pelo MTE e pela } \\
\text { CONATRAE com os dados da fiscalização fundiária, com foco } \\
\text { em obtenção de áreas (descumpridoras da função social da } \\
\text { propriedade). }\end{array}$ \\
\hline $\begin{array}{l}\text { Os trabalhadores resgatados foram incorporados como público } \\
\text { alvo na reforma agrária (Lei } n \text {. } 8629 / 93 \text { ). }\end{array}$ \\
\hline $\begin{array}{l}\text { Processos de fiscalização abertos no Incra a partir de dados } \\
\text { fornecidos pelo MTE. }\end{array}$ \\
\hline $\begin{array}{l}\text { Edição da Portaria n. 12, prevendo inibiçóes cadastrais, com } \\
\text { fundamento em irregularidades apuradas em processos de } \\
\text { fiscalização. }\end{array}$ \\
\hline $\begin{array}{l}\text { Edição de normativos visando a operacionalização da política } \\
\text { Instruçăo Normativa } 83 / 2015\end{array}$ \\
\hline CONATRAE \\
\hline Envio de informações ao Incra. \\
\hline $\begin{array}{l}\text { Atuação para aprovação da Proposta de Emenda Constitucional } \\
\text { do trabalho escravo que, em } 2014 \text {, por meio da Emenda } \\
\text { Constitucional n. 81, alterou o artigo } 243 \text { da Constituição } \\
\text { Federal (pendente de regulamentação legal). }\end{array}$ \\
\hline $\begin{array}{l}\text { Sensibilização do Congresso Nacional, evitando uma regressão } \\
\text { do conceito de trabalho análogo ao de escravo. }\end{array}$ \\
\hline
\end{tabular}

Fonte: Elaboração dos autores.

Por fim, considerando que uma rede envolve também a construção de um objetivo maior que se torna um valor compartilhado entre os atores que a integram, a pesquisa evidenciou que o Incra e a CONATRAE percebem de modo semelhante o problema, o que pode influenciar nos resultados das políticas públicas (Börzel, 1998). De fato, apesar de apresentarem estratégias distintas de atuação, pois são entes autônomos com diferentes inserções institucionais (Monteiro \& Fleury, 2014), a pesquisa revelou que existe um consenso entre os integrantes do grupo de que a reforma agrária é um instrumento importante de combate ao trabalho escravo, importância destacada por 4 (quatro) dos 7 (sete) participantes do grupo, a exemplo:

"Se a gente de fato fizesse um processo de reforma agrária (...) não sei nem se a gente iria estar falando (sic) de trabalho escravo, porque a reforma agrária é além da terra, muito além da terra. Você teria um conjunto de política públicas para fixar os camponeses no campo". (Participante 6)

"É obvio que a reforma agrária é um componente a ser analisado quando se estuda o trabalho escravo (...) a reforma agrária na perspectiva do que se discute, só a terra, ela por si só não resolve, mas a reforma agrária na perspectiva do que a gente entende ser adequada, ela, sim, de fato permitiria que a gente erradicasse sim o trabalho escravo". (Participante 1)

Os participantes do grupo focal que não externaram verbalmente esta compreensão demonstraram concordar com a ideia de que uma reforma agrária efetiva é instrumento relevante no combate ao trabalho escravo.

\section{Conclusões}

O presente estudo objetivou analisar em que medida as estratégias de formalização de atores em redes de políticas públicas geram efetivas participações e atuações no policy making. O estudo focou no caso da rede 
constituída para a execução de ações relacionadas à promoção de reforma agrária como instrumento de combate ao trabalho escravo.

A pesquisa mostrou que a inclusão formal, ou de jure, não gera, necessariamente, o envolvimento de facto de todos indicados no Plano na implementação das ações. Esse achado é relevante, na medida em que ressalta a dissociação entre a formalização da política e a sua efetiva dinâmica, que possui, ao mesmo tempo, atores informais e instituições que parecem não agir conforme o Plano estabelecia, uma atuação articulada entre os atores responsáveis e parceiros, sobretudo integrantes do poder público. Uma das causas verificadas para tanto foi a falta de precisão do II PNETE na indicação de responsabilidades de cada ator.

Constatou-se ainda a existência de articulação precária entre Incra e CONATRAE e entre estes e outros atores, especialmente o MTE. Observou-se que a rede de atores analisada possui fragilidades em seu padrão organizativo, uma vez que nem todos os atores indicados no Plano foram identificados pelo grupo. Isso sugere a inexistência de vínculos entre todos os atores que poderiam contribuir para a efetivação das ações do II PNETE ou um conhecimento parcial dos participantes do grupo da rede de atores responsáveis por essas ações.

Os resultados indicam também que os relacionamentos entre os atores ocorrem mais por meio de troca de informações. Neste ponto, restou demonstrada uma falta de alinhamento normativo-operacional e institucional formal para a troca e (ou) intercâmbio de dados, haja vista que as ligações que fundamentam essa troca não são previstas em normativos que esclareçam o fluxo e determinem o conteúdo de dados a serem compartilhados e nem a forma de tratamento deles quando recebidos. Além disso, esse intercâmbio ocorria muitas vezes de maneira informal, determinado pela proximidade entre as pessoas, limitação que também foi encontrada no estudo de Monteiro e Fleury (2014).

Percebe-se, ainda, que a atuação do Incra no âmbito do II PNETE depende de provocações de outros atores, em razão da ausência de clareza quanto à sua competência e limites de sua atuação. Especificamente na fiscalização do cumprimento da função social da propriedade no aspecto trabalhista, o Incra depende das indicações do MTE, a partir das ações de fiscalizações desenvolvidas pelo Ministério.

Com vistas a superar esta dificuldade, o Incra editou norma interna que descreve procedimentos para desapropriação para fins de reforma agrária dos imóveis constantes da "Lista Suja" do Ministério do Trabalho e Emprego (Instrução Normativa 83, 2015). A norma, entretanto, foi questionada e chegou a ter a aplicação dos dispositivos referidos suspensa.

Também foi citado pelos servidores a ausência de capacitação dos mesmos e de planejamento estratégico que inclua a priorização das ações de reforma agrária com foco no combate ao trabalho escravo no órgão.

A análise das falas dos participantes da pesquisa permitiu a identificação dos valores compartilhados entre Incra e CONATRAE, revelando que existe um consenso entre os integrantes do grupo de que a reforma agrária é um instrumento importante de combate ao trabalho escravo, apesar desses atores apresentarem estratégias distintas de atuação, serem autônomos e com diferentes inserções institucionais.

Por fim, o mapa construído a partir das informações coletadas (Figura 1) sugere um papel relevante e central para a CONATRAE, considerando o número de vínculos que tem a Comissão com os demais atores. Por outro lado, não foram identificados muitos vínculos do Incra com os demais atores, apesar de ser a autarquia o ator responsável pela efetivação das ações de reforma agrária, sugerindo que a criação de novos vínculos e o fortalecimento dos mesmos constituem estratégias necessárias para uma melhor implementação da política. O mapa demonstra que, apesar do papel institucional do Incra ser central, esse ator carece de um melhor relacionamento com os demais atores que podem colaborar com a execução da política.

Cabe salientar que a pesquisa confirmou a utilidade teórica da análise de redes para investigação e avaliação de processos de implementação políticas públicas (Frey et al., 2005), permitindo o avanço na compreensão de como as políticas públicas são de fato executadas, bem como dos desafios trazidos à gestão pública em arranjos complexos e dinâmicos como no caso do II PNETE (Fleury, 2005). 
Como limitação da pesquisa, é importante reconhecer a dificuldade de reunir todos os convidados para participar do grupo focal, a ausência de servidores do Incra que atuam junto à Coordenação-Geral de Obtenção de Terras, bem como de outros servidores que atuaram na Coordenação da CONATRAE. Nesse sentido, os resultados precisam ser ponderados e analisados com cautela, uma vez que refletem a perspectiva de atores centrais na política, mas não representam todos os envolvidos.

Não obstante, de modo geral, o estudo traz contribuições ao campo na medida em que demonstrou que o foco das análises, mais especificamente aquelas que pressupõem o funcionamento em redes, deve atentar não apenas para a dimensão formal da constituição e do funcionamento do processo de implementação de uma política pública. É justamente no olhar da prática cotidiana das organizações envolvidas que se observa os resultados e dificuldades no policy making. Além disso, a pesquisa também serviu como um bom diagnóstico para se detectar lacunas e incongruências na coordenação intragovernamental e extragovernamental, sobretudo porque um problema complexo e multicausal como o trabalho escravo contemporâneo depende de ações colaborativas para o seu enfrentamento. $\mathrm{O}$ mapeamento do grau de engajamento dos atores e do real funcionamento da rede possibilita propor medidas que potencializem os impactos das ações do Plano.

Para pesquisas futuras, sugere-se a investigação junto a outros atores responsáveis pelas ações do II PNETE que envolvem reforma agrária como instrumento de combate ao trabalho escravo, indicados no próprio II PNETE e pelos participantes do grupo focal, a fim de colher a percepção dos participantes das demais entidades envolvidas nessas ações. Considerando a não especificação de entidades da sociedade civil pelo II PNETE e a ausência de indicação de outras entidades além da CPT e da SMDH, a inclusão em pesquisas futuras de algumas entidades participantes da CONATRAE, a exemplo da organização não-governamental (ONG) Repórter Brasil, que participou da organização da Plataforma de monitoramento das ações do II PNETE, hoje alimentada pela CONATRAE, também pode trazer reflexões relevantes para a compreensão da política.

\section{REFERÊNCIAS}

II Plano Nacional para a Erradicação do Trabalho Escravo. (2008). Brasília, DF: Secretaria Especial dos Direitos Humanos.

Bicudo, H. (2008). Reflexões sobre trabalho escravo no Brasil. In Cerqueira, G. C., Figueira, R. R., Prado, A. A., \& Costa, C. M. L. (Org.). Trabalho escravo contemporâneo no Brasil: contribuiçôes críticas para sua análise e denúncia. Rio de Janeiro, RJ: UFRJ.

Bispo, F. C. S., \& Santos, A. B., Jr. (2017). Redes e políticas públicas: reflexões teóricas e desafios futuros. Anais do Encontro da ANPAD, São Paulo, SP, Brasil, 41.

Börzel, T. A. (1998). Organizing Babylon - On the different conceptions of policy networks. Public Administration, 76(2), 253-273.

Brito, J. C. M., Filho. (2010). Trabalho decente. São Paulo, SP: LTr.

Collis, J., \& Hussey, R. (2005). Pesquisa em administração: um guia prático para alunos de graduação e pós-graduação (3a ed.). Porto Alegre, RS: Bookman.

Creswell, J. W. (2010). Projeto de pesquisa: métodos qualitativo e quantitativo (3a ed.). Porto Alegre, RS: Artmed.

Decreto de 31 de julho de 2003. (2003). Cria a Comissão Nacional de Erradicação do Trabalho Escravo CONATRAE. Brasília, DF. Recuperado de http://www.planalto.gov.br/ccivil_03/DNN/2003/Dnn9943.ht $\mathrm{m}$.

Decreto-Lei n. 1.110, de 9 de julho de 1970. (1970). Cria o Instituto Nacional de Colonização e Reforma Agrária (INCRA), extingue o Instituto Brasileiro de Reforma Agrária, o Instituto Nacional de Desenvolvimento Agrário e o Grupo Executivo da Reforma Agrária e dá outras providências. Brasília, DF. Recuperado de http://www.pl analto.gov.br/ccivil_03/decreto-Lei/1965-1988/Del1110.htm. 
Figueira, R. R. (2004). Pisando fora da própria sombra: a escravidão por divida no Brasil contemporâneo. Rio de Janeiro, RJ: Civilização Brasileira.

Fleury, S. (2005). Redes de políticas: novos desafios para a gestão pública. Revista Administração em Diálogo - RAD, $7(1), 77-89$.

Fleury, S., \& Ouverney, A. M. (2007). Gestão de redes: a estratégia de regionalização da politica de saúde. Rio de Janeiro, RJ: FGV.

Frey, K., Penna, M. C., Czajkowski, S., Jr. (2005). Redes de políticas públicas e sua análise. Anais do encontro anual ANPOCS, Caxambu, MG, Brasil, 29.

Genoino, R. K., \& Siqueira, J. P. L. (2016). Gestão pública em redes e a nova governança pública: a implementação de parcerias entre o poder público e o terceiro setor. Revista Capital Científico-Eletrônica, 14(3), 132-143.

Gil, A. C. (2008). Métodos e técnicas de pesquisa social (3a ed.). São Paulo, SP: Atlas.

Hair, J. F., Jr., Barry, B., Money, A. H., Samouel, P. (2005). Fundamentos de métodos de pesquisa em administração. Porto Alegre: Bookman.

Koppenjan, J., Klijn, E. H. (2004). Managing uncertainties in networks: a network approach to problem solving and decision making. Londres: Routledge.

Lima, L. L., D'Ascenzi, L. (2013). Implementação de políticas públicas: perspectivas analíticas. Revista de Sociologia e Politica, 21(48), 101-111.

Monteiro, L. A., Fleury, S. (2014). Elos que libertam: redes de políticas para erradicação do trabalho escravo contemporâneo no Brasil. Organizações \& Sociedade, 21(69), 255-273.

Organização Internacional do Trabalho. (2007). O Trabalho Escravo no Brasil do Século XXI. Brasília, DF.

Organização Internacional do Trabalho. (2011). Perfil dos principais atores envolvidos no trabalho escravo rural no Brasil. Brasília, DF.

Organização das Nações Unidas. (2016). Trabalho escravo. Recuperado de https://nacoesunidas.org/wp-content/up loads/2016/04/position-paper-trabalho-escravo.pdf.

Sampieri, R. H., Collado, C. F., Lucio, M. P. B. (2013). Metodologia de pesquisa (5a ed). São Paulo, SP: McGraw-Hil.

Schneider, V. (2005). Redes de políticas públicas e a condução de sociedades complexas. Civitas-Revista de Ciências Sociais, 5(1), 29-58.

Silva, S. S., Coto, G. C. (2015). Redes públicas de cooperação e o desenvolvimento local: a experiência do Programa Nacional de Habitação Rural (PNHR) no Alto Vale do Itajaí. Revista de Ciências da Administração, 17(1), 165-182.

Vergara, S. C. (2005). Métodos de pesquisa em Administração. São Paulo, SP: Atlas.

\section{BY-NC-ND}

